\title{
İşletmelerin Finansal Başarılı ve Başarısız Olma Durumlarının Veri Madenciliği ve Lojistik Regresyon Analizi İle Tahmin Edilebilirliği
}

\author{
Estimation Capability of Financial Failures and Successes of Enterprises Using Data \\ Mining and Logistic Regression Analysis \\ Ceyda YERDELEN KAYGIN', Alper TAZEGÜL2², Hakan YAZARKAN³
}

\section{ÖZET}

Günümüz koşulları göz önüne alındığında işletmelerin hedeflerini gerçekleştirebilmeleri için finansal açıdan güçlü olmaları gerekmektedir. $\mathrm{Bu}$ nedenle finansal başarısızlıklarının tahmin edilmesi, işletmelerin gelecekte oluşabilecek finansal riskleri tespit etmeleri ve gerekli önlemleri almaları bakımından oldukça önemlidir. Çalışmada, Borsa İstanbul'da 2010-2013 döneminde kesintisiz olarak işlem gören 143 imalat sanayi şirketinin yıllık bilanço ve gelir tablosu verilerinden yararlanılarak işletmelerin finansal başarılı ve başarısız olma durumları tahmin edilmeye çalışılmıştır. Araştırmada Veri Madenciliği ve Lojistik Regresyon Analizi yöntemleri kullanılmıştır. 2013 yılı baz alınarak bir yıl, iki yıl ve üç yıl öncesinin tahmin edilmesine yönelik modeller geliştirilmiş ve modellerin sınıflandırma doğrulukları başka bir ifadeyle modellerin tahmin gücü karşılaştırılmıştır. Analiz sonucunda, işletmelerin finansal başarılı ve başarısız olma durumlarını tahmin etmek için oluşturulan tüm modellerde 2012 yılı tahmin gücü en başarılı yıl olarak saptanmıştır.

Anahtar Kelimeler: Finansal Başarı/Başarısızlık, Veri Madenciliği, Lojistik Regresyon Analizi

\section{ABSTRACT}

Given today's conditions, enterprises should be financially powerful in order to achieve their goals. Therefore, estimating financial failures is quite important in terms of determining possible future financial risks of enterprises and taking the required steps.

In this study, annual balance sheets and income statements of 143 manufacturing firms, which were publicly traded in Borsa Istanbul between 2010 and 2013 and which displayed continuity, were used to estimate their financial failures and successes. Data Mining and Logistic Regression Analysis methods were used in this research. Models were developed to make an estimation prior to the first, second and third years taking year 2013 as basis, and classification accuracy, in other words estimation power of these models were compared.

Among all models that were suggested to estimate failures and successes of enterprises, 2012 was determined as the year with the most successful estimation power as a result of our analysis.

Keywords: Financial Failure/Success, Data Mining, Logistic Regression Analysis 


\section{GíRiş}

Küreselleşme olgusuyla birlikte işletmeler her an şiddetlenen bir değişim ortamında faaliyette bulunmaktadırlar. Söz konusu değişime ve rekabete ayak uyduramayan işletmeler finansal açıdan başarısızlık riskiyle karşılaşmışlardır. Finansal sistem içinde yer alan işletmelerin başarısızlıkları; sadece firmaların finansal yeterliliklerinin yerine getirilebilirliğinin belirlenmesi açısından değil aynı zamanda ülke ekonomisinin başarı ölçütü olması açısından da önem arz etmektedir (Akkaya vd., 2009:187).

Başarısızlığı ekonomik başarısızlık, teknik başarısızlık, işletme başarısızlığı ve finansal başarısızlık olmak üzere farklı kavramlarla ele almak gerekmektedir. Ekonomik başarısızlık, işletmenin yatırım kârlıı̆ının sermaye maliyetinden az olması veya işletme gelirlerinin maliyetleri karşılamak için yetersiz olması şeklinde ifade edilebilir (Sharan, 2009:428). Teknik başarısızlık, işletmenin toplam varlıklarının toplam borçlarından fazla olmasına rağmen; vadesi geldiğinde işletmenin cari yükümlülüklerini yerine getirememesidir (Beaver vd., 2011:3).

Uluslararası derecelendirme kuruluşlarından Dun\&Bradstreet işletme başarısızlığını “bir işletmenin kredi sağlayanlarının kaybetmelerine ya da zarara uğramalarına neden olacak şekilde işletmenin faaliyetlerini durdurması" olarak tanımlamaktadır (Altman ve Hotchkiss, 2010:12). İşletme başarısızlığı; örgütsel ölümlülük, örgütsel ölüm, örgütsel çıkış, iflas, çöküş, kapanma ve küçülme olarak da ifade edilmektedir (Mellahi ve Wilkinson, 2004:22). İşletmelerin başarısızlığı yönetim yetersizliği, sermaye eksikliği, finansal planlama gibi işletme içi faktörlerden veya ekonomik, sosyal, kültürel ve politik unsurları kapsayan işletme dışı faktörlerden kaynaklanabilir.

Literatürde finansal sıkıntı olarak adlandırılan finansal başarısızlık ise ekonomik, teknik ve işletme başarısızığını içine alan geniş kapsamlı bir terimdir (Sharan, 2009:428). Bazı işletmelerde iflasla sonuçlanan, bazıları için ise sadece bir tehlike olarak görülen finansal başarısızlık; işletmenin hedefine ulaşamaması, borçlarını vadesinde ödeyememesi, kredibilitesini kaybetmesi yani yükümlülüklerini kısmen veya tamamen yerine getirememesiyle iflasa kadar uzanan süreci ifade etmektedir (Brealey vd., 1997:421; Okka, 2009:928).
İşletmelerin finansal başarısızlıkları, gerek ait oldukları ülkenin ekonomisini gerekse diğer ülkelerin ekonomilerini olumsuz etkilemektedir. Bundan dolayı özellikle finans literatüründe önemle üzerinde durulması gereken bir konudur ve önemini yıllar sonra bile sürdürme potansiyeline sahiptir. Buradan hareketle çalışmada, Borsa İstanbul'da 2010-2013 döneminde kesintisiz olarak işlem gören imalat sanayi şirketlerinin 2013 yılındaki finansal başarısızlık durumunun 2010, 2011, 2012 yılı verileri ile tahmin edilmesi amaçlanmıştır. Çalışmada, Veri Madenciliği ve Lojistik Regresyon Analizi yöntemi kullanılmıştır. Literatürde işletmelerin finansal başarısızlıklarının genellikle bir yıl öncesinden ve iki yıl öncesinden belirlenmesine yönelik çalışmaların olduğu görülmüştür. Bu çalışmada ise işletmelerin finansal başarısızlıkları bir yıl, iki yıl ve üç yıl öncesinden tahmin edilmeye çalışılmıştır. Ayrıca Veri Madenciliği yönteminde tahmini güçlendirmek için iki farklı algoritma kullanılmıştır. Çalışma bu yönleriyle diğer çalışmalardan farklılık göstermektedir. Yapılan analiz sonucunda her üç modelde de 2012 yılı tahmin gücü en başarılı yıl olarak tespit edilmiştir. 2012 yılı için tahmin gücü en yüksek modelin ise $\% 94,44$ doğru sınıflandırma başarısı ile Lojistik Regresyon modeli olduğu görülmüştür.

\section{LITERATÜR ÖZETI}

Tek değişkenli model kullanarak finansal başarısızlığı tahmin etmeye yönelik Beaver (1966), Tamari (1966) ve Beaver (1968) tarafından yapılan çalışmalar daha sonra yapılan çalışmalara yol göstermesi nedeniyle literatürde önemli bir yere sahiptir. Finansal başarısızlığın tahmin edilmesinde tek değişkenli modellerin finansal oranları tek tek ele alması nedeniyle incelenen orana göre çelişkili sonuçlar elde edilebilir. Bu durumdan kaçınmak isteyen araştırmacılar, çalışmalarında birden fazla finansal oranı, hatta oranlar arasındaki ilişkinin tespit edilmesine olanak sağlayan çok değişkenli modelleri kullanmışlardır. Altman (1968) çoklu diskriminant analizini, Żmijewski (1984) lojit ve probit modelleri, Ohlson (1980) lojistik regresyon analizini, Odom ve Sharda (1990) yapay sinir ağlarını kullanmışlardır.

Beaver (1966) çalışmasında 1954-1964 yılları arasında 79 başarısız işletmeyi aynı sektörlerden 79 başarılı işletme ile eşleştirmiş ve 30 finansal oran 6 grupta ve her gruptan yalnızca bir oran ele alarak değerlendirmiştir. Çalışmada bazı oranların en az beş yıl öncesine kadar başarısızlığı tahmin etmede 
kullanılabileceği sonucuna ulaşılmıştır.

Tamari (1966) tek bir değişkenin yerine birden fazla değişken kullanarak 1956-1960 dönemini kapsayan çalışmasında, yeni iflas etmiş 12 işletme ile iflasını isteyen 16 endüstri işletmesinin verilerini kullanmıştır. Tamari finansal oranlardan yararlanarak risk indeksi oluşturmuş ve işletmelerin finansal başarılarını ifade ederken işletmeleri 0 ile 100 arasında puanlandırmıştır. Çalışmanın sonucunda risk indeks modeline göre 30 puandan daha az olan işletmelerin $\% 50$ 'si, 30 puandan daha fazla olan işletmelerin ise \%3'ünün iflas ettiğini gözlemlemiştir.

Altman (1968) Çoklu Diskrimant Analizini kullanarak 1946- 1965 yılları arasında iflas etmiş ve aktifleri 0,7-25,9 milyon dolar arasında olan üretim işletmelerini ve aynı endüstri kolunda yer alan aktifleri 1-25 milyon dolar arasında olan işletmeleri iki grup halinde eşleştirerek incelemiştir. Çalışma sonucunda işletmelerin iflasının, bir yıl öncesi için \%95, iki yıl öncesi için \%72 oranında tahmin edilebildiği saptanmıştır.

Ohlson (1980) 1970 -1976 yılları arasında 105 iflas etmiş ve 2058 iflas etmemiş işletmenin verilerini kullanarak lojistik regresyon analizi yöntemiyle işletmelerin iflasını tahmin etmeye çalışmıştır. Çalışma sonucunda iflastan bir yıl öncesi için, iflastan iki yıl öncesi için ve iflastan bir ve iki yıl öncesini birleştirerek kurduğu farklı modellerde sırasıyla \%96,12; \%95,55 ve $\% 92,84$ oranında başarılı tahminler elde etmiştir.

Odom ve Sharda (1990) 1975-1982 yılları arasında 65 iflas etmiş, 64 iflas etmemiş toplam 129 işletmenin verilerinden yararlanarak doğru sınıflandırma performansını ölçmek için yapay sinir ağı modeli ile sonuçları karşılaştırmışlardır. Çalışmada yapay sinir ağları yönteminin diskriminant analizine göre daha doğru sınıflandırma performansına sahip olduğu sonucuna varılmıştır. Çalışma sonucunda yapay sinir ağları modeli ile eğitim setine bağlı olarak iflas etmiş işletmelerin \%77,78-\%81,48 oranında, iflas etmemiş işletmelerin ise $\% 78,57-\% 85,71$ oranında doğru sınıflandırıldığı tespit edilmiştir.

Shirata (1998) çalışmasında 1986-1996 yılları arasında 686 iflas etmiş, 300 iflas etmemiş Japon firmasının veri madenciliği yöntemi ile 61 tane finansal oran kullanarak finansal başarısızlık riskini incelemiştir. Çalışma sonucunda modelin doğru sınıflandırma başarısı \%86,14 olarak belirlenmiştir.

Atiya (2001) yaptığı çalışmada, şirket başarısızlıklarının tahmin etmek için finansal verileri kullanmış ve Sinir Ağı yöntemi ile bir model oluşturmuştur. Modelinin üç yıllık tahmin döneminde her bir dönem için doğru sınıflandırma oranı $\% 81,46$ ile $\% 85,5$ arasında olduğu tespit edilmiştir.

Tang ve Chi (2005) 1995 ve 2002 yıllar arasında Shenzhen ve Shanghai Borsasında işlem gören 128 başarılı ve 128 başarısız olmak üzere toplam 256 şirketin Sinir Ağı Analizi ile işletme başarısızlıklarını tahmin etmeye çalışmışlardır. Çalışma sonucunda başarısızlık tahmin modellerinin sektörler arasında ve sektöre özgü şartlarda iyi bir sınıflandırma yeteneği sağlayabileceğini saptamışlardır.

Li ve Sun (2011) çalışmalarında Shenzhen ve Shanghai Borsasına kayıtlı 135 başarılı ve 135 başarısız şirketin Lojistik Regresyon ve Dikriminant Analizi ile işletme başarısızlıklarını tahmin etme performansını belirlemeye çalışmışlardır. Ortaya çıkan sonuçlarda, modellerin Çin'deki şirketlerin kısa dönemli işletme başarısızlık tahminlerinde üstün öngörümlenebilen bir performans ortaya koyabileceği görülmüştür.

Siedlecki (2014) çalışmasında Polonya piyasasında yer alan büyük ve tanınmış başarılı bir şirket ile iflas etmiş bir şirketin 2001-2010 yılları arasındaki finansal verilerini kullanarak şirketlerin finansal başarısızlığını tahmin etmeye çalışmıştır. Finansal başarısızlığın tahmininde finansal verilerin kullanılıp kullanılmayacağını lojistik regresyon analizi ile test etmiştir. Çalışmada seçilmiş finansal parametrelerin finansal başarıyı değerlendirmek için çok kullanışlı olduğu ve lojistik fonksiyon birinci ve ikinci türevlerinin analizinin daha fazla şirket için test edilebilirliği sonucuna varılmıştır.

Aktaş vd. (2003) yaptıkları çalışmada 1983-1997 yılları arasında 53'ü finansal başarısız, 53'ü finansal başarısız olmayan, toplam 106 işletmeden oluşan bir örneklem oluşturmuşlardır. Çalışmada Çoklu Regresyon, Diskriminant, Logit ve Yapay Sinir Ağı modelleri geliştirmişlerdir. Araştırmada, yapay sinir ağının geçerlilik testi sonucu finansal başarısızlığı ön görme gücünün çoklu regresyon modelinden daha üstün olduğu tespit edilmiştir.

Altaş ve Giray (2005), finansal başarısızlık riski olan işletmeleri belirlemek için tekstil sektöründe faaliyet gösteren işletmelerin 2001 yılına ait bilançoları yardımıyla finansal oranları hesaplayarak bir model geliştirmişlerdir. Araştırmacıların geliştirdiği modelin doğru sınıflandırma başarısı \%74 olarak hesaplanmıştır. 
Akkaya vd. (2009) çalışmalarında yapay sinir ağları modeli ile Tekstil ve Kimya, Petrol ve Plastik Ürünleri sektörlerinde 1998-2007 döneminde faaliyet gösteren işletmelerin finansal başarısızlıklarının bir yıl öncesinden belirlenmesine yönelik bir model geliştirmişlerdir. Çalışma sonucunda modelin başarılı işletmelerin yaklaşık \%82'sini doğru tahmin ettiği görülmüştür.

Tükenmez vd. (2011) Ege Bölgesi'nde faaliyet gösteren Küçük ve Orta Ölçekli işletmelerden 180 başarılı ve 180 başarısız işletme şeklinde iki grup oluşturularak finansal başarısızlıktahmin modellerinin Küçük ve Orta Ölçekli işletmelerde tahmin başarı düzeyleri araştırılmıştır. Araştırma sonucunda Diskriminat Analizi ve CHAID yöntemlerinin birbirlerine çok yakın tahmin gücüne sahip olduğu görülürken, Lojistik Regresyon yönteminin bu iki yöntemden daha başarılı olduğu saptanmıştır.

Yakut ve Elmas (2013) çalışmalarında 20052008 yılları arasında 140 sanayi işletmesinin finansal başarısızlıklarının önceden tahmin edilebilirliğini tespit etmek için veri madenciliği ve diskriminant analizi modelleri oluşturmuşlardır. Araştırmada deney ve kontrol testi üzerinde yapılan tahmin sonuçlarına göre veri madenciliğinin diskriminant analizine göre daha iyi sonuç verdiğini saptamışlardır.

\section{YÖNTEM}

\subsection{Araştırmanın Amacı ve Kapsamı}

Bu çalışmanın amacı, Borsa İstanbul'da 2010-2013 döneminde işlem gören ve süreklilik gösteren imalat sanayi şirketlerinin finansal başarısızlıklarının bir yıl, iki yıl ve üç yıl öncesinden tahmin edilmesine yönelik Veri Madenciliği Yöntemi ve Lojistik Regresyon Analizi ile modeller geliştirmektir. Modellerde kullanılan bağımsız değişkenler; likidite, finansal yapı, faaliyet ve kârlılık oranlarından oluşan 25 adet finansal orandan oluşmaktadır. Bağımlı değişken olarak işletmelerin finansal başarı durumu, finansal başarılı işletmeler "1" ve finansal başarısız işletmeler "0" ile kodlandırılarak kullanılmaktadır.

\subsection{Veri Madenciliği}

Veri Madenciliği; büyük miktarda veri içerisinden, teknolojiyi, istatistiksel ve matematiksel teknikleri kullanarak anlamlı (değerli-gizli) ve kullanılabilir bilgilerin açığa çıkarılması olarak tanımlanmaktadır. Veri Madenciliği altı aşamalı bir süreç olarak incelenebilir. Bu aşamalar (Larose 2005; 2-7):
Araştırma probleminin tanımlanması, verileri tanıma, veri hazırlama, modelleme, değerlendirme ve uygulamadır.

Veri madenciliğinin amacı, geçmiş faaliyetlerin analizini temel alarak gelecekteki davranışların tahminine yönelik karar verme modelleri oluşturmaktır. Veri madenciliğinde farklı amaçlarla kullanılan çeşitli yöntemler bulunmaktadır. Bu yöntemlerden biri olan karar ağacı modeli, adından da anlaşıldığı gibi ağaç olarak görünen, tahminsel bir modeldir. Ağacın her dalı bir sınıflandırma sorusu ve yaprakları da veri setinin bu sınıflandırmaya ait parçalarıdır (Koyuncugil ve Özgülbaş, 2006:162). Karar ağacı algoritmalarının bağımlı ve bağımsız değişkenler arasındaki ilişkilerin yönünü, önem sırasını görselleştirmesi ve sonuçların anlaşılır, yorumlanabilir, somut ve kullanışlı olması nedeniyle günümüzde finansal çalışmalarda kullanılan bir modeldir (Albayrak ve Yılmaz, 2009:42).

Temeli AID (Automatic Interaction Detector) yöntemi ile atılan karar ağacı modellerinin; CHAID (Chi-Squared Automatic Interaction Detector), C\&RT (Classification and Regression Trees), ID3 (Quinlan), Exhaustive CHAID (Biggs), C4.5 (Quinlan), MARS (Multivariate Adaptive Regression Splines), QUEST (Quick, Unbiased, Efficient Statistical Tree), C5.0 (Quinlan), SLIQ (Supervised Learning in Quest), SPRINT (Scalable Par alleizable Induction of Decision Trees) olmak üzere birçok algoritma literatürde yaygın olarak kullanılmaktadır.

\subsection{Lojistik Regresyon Analizi}

Finansal başarısızlık tahminlemelerinde sık sık kullanılan, çok değişkenli istatistiksel yöntemlerden biri olan ve Logit Model olarak da adlandırılan Lojistik Regresyon Analizi, bağımlı değişkenin kategorik olarak ikili, üçlü ve çoklu kategorilerde olduğu durumlarda, bağımsız değişkenlerle sebep-sonuç ilişkisini belirlemek için başvurulan bir yöntemdir (Özdamar, 2004:589). Lojistik regresyon analizi, bağımsız değişkenlerin bağımlı değişken üzerindeki etkilerini odds oranı ile açıklamaktadır. Bağımlı değişkenin alacağı iki değerden birinin diğerine karşı gerçekleşme olasılığına odds oranı denir (Özdemir, 2011:185). Bağımlı değişkenin kategorik olduğu lojistik regresyon analizinde, finansal başarısızlık tahminlemesinde başarılı olan şirketler "1"ile başarısız olan şirketler ise " 0 " ile kodlanmaktadır (Vuran, 2008:77). 
Lojistikregresyongenelolarak; $P_{i}=E\left(Y_{i}=1 X_{i}\right)=b_{0}+b_{1} X_{1 i}$ şeklinde tanımlanmaktadır. Bu şekilde tanımlanan doğrusal olasılık modelinde tahmini değerler; olasılığın koşulu olan 0 ile 1 arasında yer almamaktadır. Bu nedenle bir olayın olma olasılığının $\left(P_{i}\right)$, olmama olasılığına $\left(1-P_{i}\right)$ şeklinde formülize edildiğinde odds oranı $P_{i} /\left(1-P_{i}\right)$ ölçülmektedir. Böylece olasılığın koşulu olan 0 ile 1 arasında yer alabilmesi için lojitli dönüşümünde önce $P_{i} /\left(1-P_{i}\right)$ "üstünlük (odds) oranı" hesaplanarak $[0 ;+\infty)$ değerleri arasında tanımlılık oluşturulur. Odds oranı hesaplandıktan sonra değerin doğal logaritması (logit) alınarak değişkenin $(-\infty ;+\infty)$ arasında sürekli olması sağlanmaktadır (Gujarati, 2011:554-558, Tarı, 2011, 250-525). Lojistik Regresyon Modeli şu şekildedir (Vuran, 2008:78-79):

Tek bağımsız değişken olması durumunda;

$$
\operatorname{Logit}(\mathrm{Y})=\ln \frac{P_{i}}{1-P_{i}}=b_{0}+b_{1} X_{i}+e_{i}
$$

Birden fazla bağımsız değişken olması durumunda;

$$
\operatorname{Logit}(\mathrm{Y})=\ln \left(\frac{P_{i}}{1-P_{i}}\right)=b_{0}+b_{1} X_{1}+b_{2} X_{2}+\ldots b_{p} X_{p}+e_{i}
$$

Tahmini olasılık ise;

$$
P=\frac{e^{\left(b_{0}+b_{1} X_{1}\right)}}{1+e^{\left(b_{0}+b_{1} X_{1}\right)}}=\frac{1}{1+e^{-\left(b_{0}+b_{1} X_{1}\right)}} \text { şeklinde fade edilir. }
$$

\subsection{Araştırmada Kullanılan Veriler ve Değişkenler}

Çalışmada Borsa İstanbul'da 2013-2010 döneminde kesintisiz olarak işlem gören 143 imalat sanayi şirketinin yıllık bilanço ve gelir tablosu verileri kullanılarak işletmeler aşağıdaki kriterlere göre "finansal başarılı" ve "finansal başarısız" olarak sınıflandıııımıştır.

Başarısız işletmeleri tespit etmek için iflas etmek, borsada tahtası kapanmak, faaliyetlerini durdurmak, üst üste 2 ya da daha fazla yıl zarar etmek gibi kriterler esas alınmaktadır (Yakut ve Elmas, 2013:265). Çalışmada yer alan işletmelerin 39 tanesi başarısız, 104 tanesi başarılı olarak belirlenmiştir. Başarılı işletmeler "1" ve başarısız işletmeler "0" ile kodlanmıştır.

Modelleme aşamasında Bağımlı değişkenin iki durumlu (Başarılı=1, Başarısız=0) olmasından dolayı ve kullanılan modellerin başarısının ayrıca değerlendirilip en başarılı modelin tespit edilebilmesi için çalışmada Karar Ağaçları algoritmalarından CHAID ve C 5.0 yöntemleri ile Lojistik Regresyon Analizi kullanılmıştır.

Veri seti kullanılarak yapılan çalışmalarda veriler rassal olarak eğitim ve test seti olmak üzere iki kısma ayrılmaktadır. Eğitim seti modellerin oluşturulması, test seti ise oluşturulan modelin başarılarının test edilmesi amacı ile kullanılmaktadır. Tesadüfi örneklemede veri setinin yaklaşık \%70-\%75'i eğitim seti olarak ayrılmaktadır (Tsiptsis ve Chorianopoulos, 2009:26). Model oluşturmak için eğitim veri seti olarak 143 adet veri içerisinden rastgele seçilen 107 adet veri kullanılmıştır. Çalışmada verilerin $\% 75$ ile model eğitilerek geri kalan \%25'i ile test edilerek model oluşturulmuştur. Çalışmada bağımsız değişken olarak dört farklı kategoride 25 finansal oran kullanılmıştır. $\mathrm{Bu}$ oranlar belirlenirken gerek yurt içi gerekse yurt dışında yapılan çalışmalarda finansal başarısızlığı tahmin etmek için yaygın olarak kullanılan değişkenlerden faydalanılmıştır (Shirata 1998; Aktaş vd., 2003; Albayrak ve Yılmaz, 2009; Li ve Sun 2011; Yakut ve Elmas, 2013). Bunlar Tablo 1'de gösterilmiştir. 
Tablo 1: Çalışmada Kullanılan Bağımsız Değişkenler

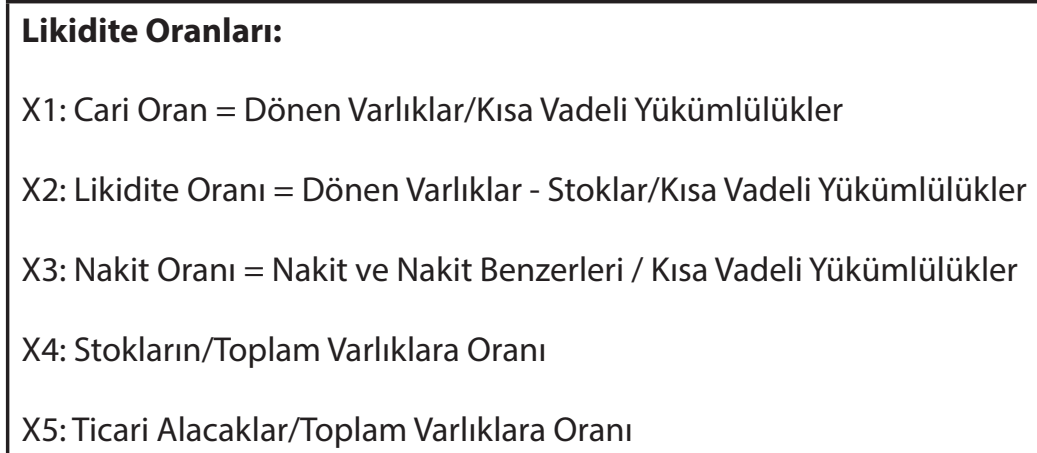




\section{BULGULAR}

2013 yılı baz alınarak modeller oluşturulmuş, firmaların 2013 yılındaki finansal başarısızlık durumu 2010, 2011, 2012 yılı verileri ile tahmin edilmeye çalışılmış ve modellerin sınıflandırma doğrulukları karşılaştırılmıştır. Tablo 2'de şirketlerin 4 yıllık verileri ile oluşturulan modellerle şirketlerin finansal başarısızlıklarını tahmin etmede modellerin başarı durumlarını gösterilmiştir. Modelleme aşamasında Karar ağaçları algoritması olan CHAID ve C 5.0 ve Lojistik Regresyon Analizi olmak üzere 3 farklı modelleme yöntemi kullanılmıştır.

2013 yılı baz alınarak oluşturulan CHAID Modeli test verisi üzerinde uygulanmış ve 36 şirketin $28^{\prime} i$ doğru, 8'si ise yanlış sınıflandırılmıştır. Modelin başarı oranı \%77,78 olarak belirlenmiştir. Bir yıl öncesi 2012 yılı için 30'u doğru, 6'sı ise yanlış sınıflandırılmıştır. Modelin başarı oranı \%83,33 olarak hesaplanmıştır. İki yıl öncesi 2011 yılı için 28'i doğru, 8'i ise yanlış sınıflandırılmıştır. Modelin başarı oranı \%77,78 olarak bulunmuştur. Üç yıl öncesi 2010 yılı için 28'i doğru, 8'i ise yanlış sınıflandırılmıştır. Modelin başarı oranı ise \%77,78 olarak saptanmıştır.

2013 yılı baz alınarak oluşturulan C 5.0 Modeli test verisi üzerinde uygulanmış ve 36 şirketin $28^{\prime} \mathrm{i}$ doğru, 8'i ise yanlış sınıflandırılmıştır. Bu durumda modelin başarı oranı \%77,78 olarak belirlenmiştir. Bir yıl öncesi 2012 yılı için 32'si doğru, 4'ü ise yanlış sınıflandırıımıştır. Modelin başarı oranı $\% 88,89$ olarak hesaplanmıştır. İki yıl öncesi 2011 yılı için 29'u doğru, 7'si ise yanlış sınıflandırılmıştır. Modelin başarı oranı \%80,56 olarak bulunmuştur. Üç yıl öncesi 2010 yılı için 24'ü doğru, 12'si ise yanlış sınıflandırılmıştır. Modelin başarı oranı ise $\% 66,67$ olarak saptanmıştır.

2013 yılı baz alınarak oluşturulan Lojistik Regresyon Modeli test verisi üzerinde uygulanmış ve 36 şirketin 29'u doğru, 7'si ise yanlış sınıflandırılmıştır. $\mathrm{Bu}$ durumda modelin başarı oranı \%80,56 olarak belirlenmiştir. Bir yıl öncesi 2012 yılı için 34'ü doğru, 2'si ise yanlış sınıflandırıımıştır. Modelin başarı oranı \%94,44 olarak hesaplanmıştır. İki yıl öncesi 2011 yılı için 28'i doğru, 8'i ise yanlış sınıflandırılmıştır. Modelin başarı oranı \%77,78 olarak bulunmuştur. Üç yıl öncesi 2010 yılı için $25^{\prime} \mathrm{i}$ doğru, $11^{\prime} \mathrm{i}$ ise yanlış sınıflandırılmıştır. Modelin başarı oranı ise \%69,44 olarak saptanmıştır.

Çalışmada 4 yıl için farklı modeller ile yapılan tahminler sonucunda her model için 2012 yılı verilerinin finansal başarısızlığı tahmin etmede en etkili yıl olduğu tespit edilmiştir. Bu nedenle 2012 yılı sonuçları her üç model için ayrıntılı olarak incelenmiştir.

\subsection{Yılı CHAID Modelinin Sonuçlarının Değerlendirilmesi}

Uygulanan CHAID metodu sonucunda model başarıları üzerinde etkili iki değişken olduğu görülmüştür. Bu değişkenler veri setinde "X25" ve "X20" olarak kodlanmıştır. "X25: Toplam Varlıkların Kârlılığı Oranı" iken, "X20: Brüt Kâr Marjı" dır. Analiz sonucunda oluşan diyagram aşağıda verilmiş̧ir.

Tablo 2: Çalışmada Kullanılan Model Başarıları

\begin{tabular}{|c|c|c|c|c|c|c|c|}
\hline \multirow{4}{*}{2010} & \multicolumn{7}{|c|}{ Model Başarıları } \\
\hline & \multirow{3}{*}{$\begin{array}{l}\text { Doğru Sınıflanan } \\
\text { Yanlış Sınıflanan }\end{array}$} & \multicolumn{2}{|c|}{ CHAID } & \multicolumn{2}{|c|}{ C 5.0} & \multicolumn{2}{|c|}{ Lojstik Regresyon } \\
\hline & & 28 & 77,78 & 24 & 66,67 & 25 & 69,44 \\
\hline & & 8 & 22,22 & 12 & 33,33 & 11 & 30,56 \\
\hline \multirow{2}{*}{2011} & Doğru Sınıflanan & 28 & 77,78 & 29 & 80,56 & 28 & 77,78 \\
\hline & Yanlış Sınıflanan & 8 & 22,22 & 7 & 19,44 & 8 & 22,22 \\
\hline \multirow{2}{*}{2012} & Doğru Sınıflanan & 30 & 83,33 & 32 & 88,89 & 34 & 94,44 \\
\hline & Yanlış Sınıflanan & 6 & 16,67 & 4 & 11,11 & 2 & 5,56 \\
\hline \multirow{2}{*}{2013} & Doğru Sınıflanan & 28 & 77,78 & 28 & 77,78 & 29 & 80,56 \\
\hline & Yanlış Sınıflanan & 8 & 22,22 & 8 & 22,22 & 7 & 19,44 \\
\hline
\end{tabular}


Şekil 1: CHAiD Algoritması Ağaç Diyagramı

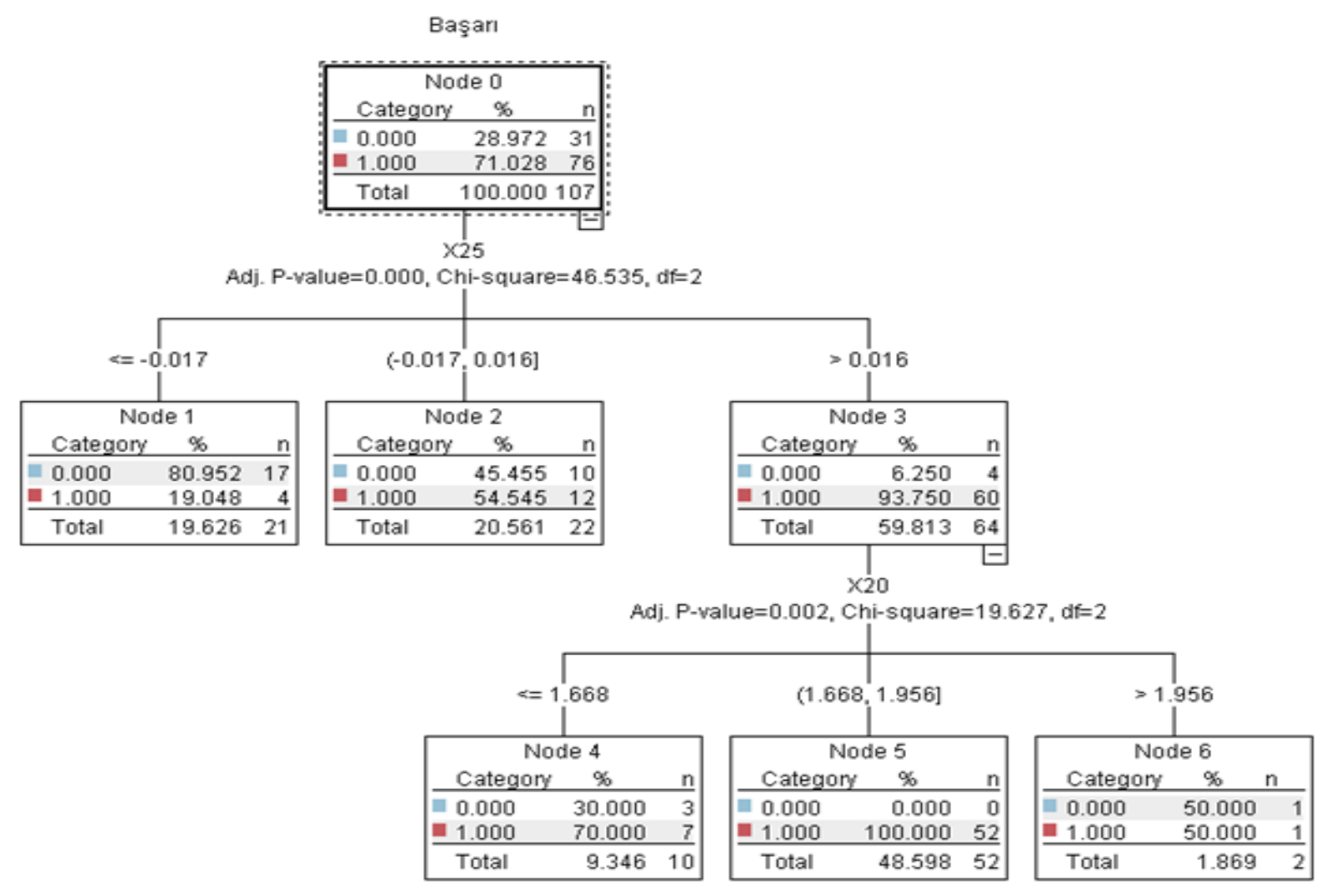

Başlangıç durumunda şirketlerin \%29'u başarısız iken, \%71'i başarılıdır. Şirket başarıları üzerinde en önemli değişken "X25"'tir ve ilk kırımı bu değişkene göre yapılmıştır. X25 değişkeni 3 grup olarak bölünmüştür. Buna göre Toplam Varlıkların Kârlılığı Oranı $-0,017$ ve altında olan şirketlerin \%81'i başarısız iken, Toplam Varlıkların Kârlılığı Oranı $-0,017$ ve 0,016 arasında olan şirketlerin \%45'i başarısızdır.

Toplam Varlıkların Kârlıığı Oranı 0,016'dan yüksek olan şirketler için "X20" değişkeni önemli olarak tespit edilmiştir. Buna göre; Toplam Varlıkların Kârlıığı Oranı 0,016'dan yüksek olan ve Brüt Kâr Marjı 1,668'den düşük olan şirketlerin \%70'i başarılı iken, Brüt Kâr Marjı 1,668 ile 1,956 arasında olan şirketlerin \%100'ü başarılıdır. Brüt Kâr Marjı 1,956'dan yüksek olan şirketlerin ise \%50'si başarılıdır.
Oluşturulan model test verisi üzerinde uygulanmış ve 36 şirketin 30'u doğru olarak sınıflandırılmış ve 6'sı ise yanlış sınıflandırılmıştır. Bu durumda modelin başarı oranı \%83,3 olarak gerçekleşmiştir.

\subsection{Yılı C 5.0 Modelinin Sonuçlarının Değerlendirilmesi}

Uygulanan C 5.0 metodu sonucunda şirket başarıları üzerinde etkili dört değişken olduğu görülmüştür. Bu değişkenler veri setinde "X22", "X12", "X8",'X4" ve "X14" olarak kodlanmıştır. "X22: Net Kâr Marjı", "X12: Toplam Borç/Toplam Varlık", "X8: Duran Varlıklar/Öz Kaynaklar", "X4: Stokların/ Toplam Varlıklara Oranı”, "X14: Ortalama Tahsil Süresi” dir. Analiz sonucunda oluşan diyagram aşağıda verilmiştir. 
Şekil 2: C5.0 Algoritması Ağaç Diyagramı

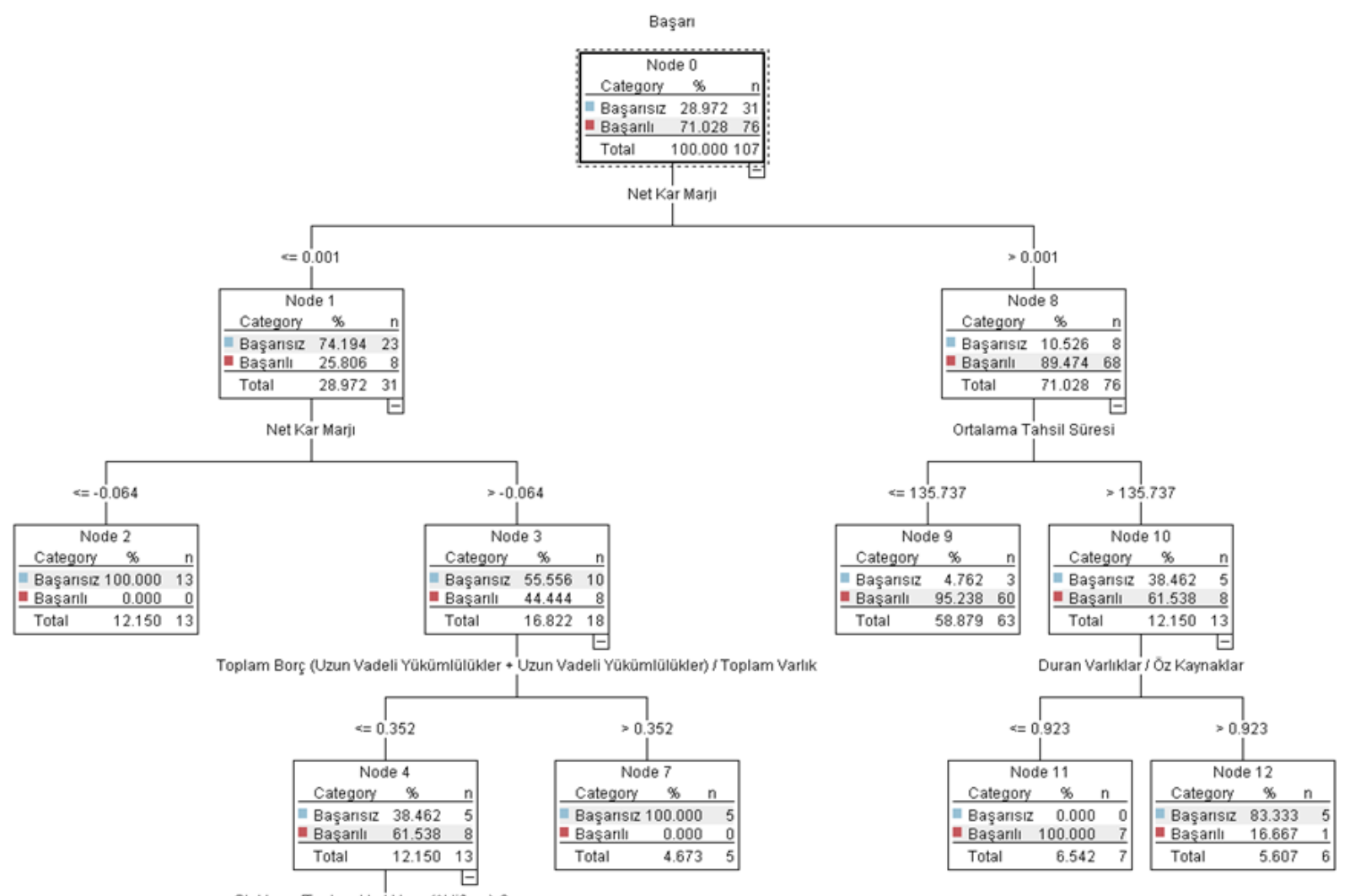

Başlangıç durumunda şirketlerin \%29'u başarısız iken, \%71'i başarılıdır. Şirket başarıları üzerinde en önemli değişken "Net Kâr Marj" dır ve ilk kırımı bu değişkene göre yapılmıştır. İki grup olarak ayrılmış ve Net Kâr Marjı 0,001'den küçük ve 0,001'den büyük olan şirketler olarak ayrılmıştır. Net Kâr Marjı 0,001'den düşük olan şirketler tekrar Net Kâr Marjına göre kırılmıştır. Net Kâr Marjı -0,064'ten küçük olan şirketlerin \%100'ünün başarısız olduğu tespit edilmiştir.

Net Kâr Marjı -0,064'ten büyük olan değerler Toplam Borç/Toplam Varlıklara göre tekrar kılırmış ve Toplam Borç/Toplam Varlıkları 0,352'den büyük olan şirketlerin $\% 100$ 'ünün başarısız olduğu tespit edilmiştir. Toplam Borç/Toplam Varlıkları 0,352'den büyük olan değerler Stokların Toplam Varlıklara Oranına göre kırılmış ve 0,261 değerinin altında olan şirketlerin \%80'inin başarılı, 0,261 değerinin üstünde olan şirketlerin \%100'ü başarısızdır.

Net Kâr Marjı 0,001'den büyük olan ve Ortalama Tahsil Süreleri 135,737 'den düşük olan şirketlerin \%95,2'si başarılıdır. Ortalama Tahsil Süreleri 135,737'den yüksek olan şirketlerden Duran Varlıkların Öz Kaynaklara oranı 0,923'ten düşük olan şirketlerin 100\%'ü başarılı iken, 0,923'ten küçük olan şirketlerin $83,4 \%$ 'ü başarısızdır.

Oluşturulan model test verisi üzerinde uygulanmış ve 36 şirketin 32'si doğru olarak sınıflandırılmış ve 4'ü ise yanlış sınıflandırılmıştır. Bu durumda modelin başarı oranı $\% 88,9$ olarak gerçekleşmiştir.

\subsection{Yılı Lojistik Regresyon Modelinin Sonuçlarının Değerlendirilmesi}

Uygulanan lojistik regresyon metodu sonucunda şirket başarıları üzerinde etkili iki değişken olduğu görülmüştür. Bu değişkenlerveri setinde "X11"ve"X24" olarak kodlanmıştır. "X11: Uzun Vadeli Yükümlülükler/ Toplam Varlıklar" iken, "X24: Esas Faaliyet Kârı Zararı/ Toplam Kaynaklar'dır. Analiz sonucunda oluşan model ve değişkenlerin tabloları aşağıda verilmiştir. Illeri doğru adımsal metot (forwards) kullanılarak değerlendirilen lojistik regresyon metodunda en uygun modelin 4. adımda X11 ve X24 değişkenleri ile kurulan model olduğu görülmektedir $(p<0,05)$. 
Tablo 3: Model Katsayılarının Omnibus Testi

\begin{tabular}{|l|c|c|c|c|}
\hline \multirow{4}{*}{ Step 1 } & Chi-square & df & Sig. \\
\hline & Step & 44,269 & 1 &, 000 \\
\cline { 2 - 5 } & Block & 44,269 & 1 &, 000 \\
\cline { 2 - 5 } & Model & 44,269 & 1 &, 000 \\
\cline { 2 - 5 } Step 2 & Step & 6,195 & 1 &, 013 \\
\cline { 2 - 5 } & Block & 50,464 & 2 &, 000 \\
\cline { 2 - 5 } & Model & 50,464 & 2 &, 020 \\
\cline { 2 - 5 } & Step & 5,375 & 1 &, 000 \\
\hline \multirow{3}{*}{ Step 4 } & Block & 55,838 & 3 &, 000 \\
\cline { 2 - 5 } & Step & 55,838 & 3 &, 258 \\
\cline { 2 - 5 } & Block & $-1,281$ & 1 &, 000 \\
\hline
\end{tabular}

Anlamlı çıkan lojistik regresyon modeli ise; $Y=(-9,166) . X 11+(30,443) . X 24+1,406$ olarak bulunmuştur.

Tablo 4: Lojistik Regresyon Modelindeki Değişkenler

\begin{tabular}{|l|c|c|c|c|c|c|}
\hline \multicolumn{2}{|c|}{} & B & S.E. & Wald & Sig. & Exp(B) \\
\hline \multirow{4}{*}{ Step 1 } & $\mathbf{X 2 5}$ & 28,773 & 6,627 & 18,852 &, 000 & 3131778649496,755 \\
\cline { 2 - 7 } & Constant &, 482 &, 278 & 2,997 &, 083 & 1,619 \\
\hline \multirow{4}{*}{ Step 2 } & $\mathbf{X 1 1}$ & $-6,292$ & 2,737 & 5,283 &, 022 &, 002 \\
\cline { 2 - 7 } & $\mathbf{X 2 5}$ & 29,117 & 7,024 & 17,185 &, 000 & 4420993838360,817 \\
\cline { 2 - 7 } & Constant & 1,328 &, 466 & 8,125 &, 004 & 3,774 \\
\cline { 2 - 7 } & $\mathbf{X 1 1}$ & $-8,416$ & 3,082 & 7,454 &, 006 &, 000 \\
\cline { 2 - 7 } & $\mathbf{X 2 4}$ & 21,614 & 10,005 & 4,667 &, 031 & 2435976423,685 \\
\cline { 2 - 7 } & Constant & 1,357 &, 494 & 7,547 &, 006 & 98368,287 \\
\hline \multirow{4}{*}{ Step 3 } & $\mathbf{X 1 1}$ & $-9,166$ & 3,008 & 9,284 &, 002 & 3,885 \\
\cline { 2 - 7 } & $\mathbf{X 2 4}$ & 30,443 & 7,183 & 17,963 &, 000 & 16649822265989,870 \\
\cline { 2 - 7 } & Constant & 1,406 &, 489 & 8,249 &, 004 & 4,079 \\
\hline
\end{tabular}

Oluşturulan modelde“Uzun VadeliYükümlülükler/ Toplam Varlıklar "1 birim arttıkça başarı olasılığı 9.166 kat azalmakta iken "Esas Faaliyet Kârı Zararı/Toplam Kaynaklar" 1 birim arttığında ise başarı olasılığı 30,443 kat artmakta olduğu görülmüştür.

Çalışmada modelleme yöntemleri ve yıllarına göre model başarısında farklı değişkenlerin etkili olduğu görülmektedir. Tablo 5'de modelleme aşamasında X2, X5, X13, X16, X17, X18, X19 ve X21 değişkenlerinin işletmelerin finansal başarılı ve başarısız olma durumlarını tahmin etmek için oluşturulan modellerde yer almadığı görülmektedir. X4, X11, X15, X22, X23 ve X25 değişkenlerinin ise modelde sıklıkla yer aldığı saptanmıştır. 
Tablo 5: Çalışmada Kullanılan Modeller İçin Önemli Değişkenler

\begin{tabular}{|l|c|c|c|}
\hline & CHAID & C 5.0 & Lojistik Regresyon \\
\hline $\mathbf{2 0 1 0}$ & $\mathrm{X} 7, \mathrm{X} 25, \mathrm{X} 8, \mathrm{X} 4, \mathrm{X} 23$ & $\mathrm{X} 4, \mathrm{X} 23, \mathrm{X} 11, \mathrm{X} 15, \mathrm{X} 1, \mathrm{X} 9$ & $\mathrm{X} 4, \mathrm{X} 11, \mathrm{X} 14, \mathrm{X} 24, \mathrm{X} 25$ \\
\hline $\mathbf{2 0 1 1}$ & $\mathrm{X} 25, \mathrm{X} 22$ & $\mathrm{X} 22$ & $\mathrm{X} 22, \mathrm{X} 25$ \\
\hline $\mathbf{2 0 1 2}$ & $\mathrm{X} 25, \mathrm{X} 20$ & $\mathrm{X} 22, \mathrm{X} 12, \mathrm{X} 8, \mathrm{X} 4, \mathrm{X} 14$ & $\mathrm{X} 11, \mathrm{X} 24$ \\
\hline $\mathbf{2 0 1 3}$ & $\mathrm{X} 22, \mathrm{X} 9, \mathrm{X} 15, \mathrm{X} 3$ & $\mathrm{X} 15, \mathrm{X} 22$ & $\mathrm{X} 6, \mathrm{X} 10, \mathrm{X} 11, \mathrm{X} 23$ \\
\hline
\end{tabular}

\section{SONUÇ}

İşletmelerin finansal başarısızlıklarını Karar ağaçları algoritması olan CHAID ve C 5.0 ve Lojistik Regresyon Analizi yöntemi ile tahmin etmek amacıyla gerçekleştirilen bu çalışmada ulaşılan sonuçlar şu şekildedir: CHAID Modelinin doğru sınıflandırma başarısı; 2013 yılı \%77,78, bir yıl öncesi 2012 yılı $\% 83,33$, iki yıl öncesi 2011 yılı \%77,78 ve üç yıl öncesi 2010 yılı için \%77,78 olarak saptanmıştır. C 5.0 Modelinin tahmin gücü; 2013 yılı $\% 77,78$, bir yıl öncesi 2012 yllı \%88,89, iki yıl öncesi $2011 \% 80,56$ ve üç yıl öncesi 2010 yılı için \%66,67 olarak belirlenmiştir. Lojistik Regresyon Modelinin öngörü gücü; 2013 yılı $\% 80,56$, bir yıl öncesi 2012 yılı \%94,44, iki yıl öncesi 2011 yılı \%77,78 ve üç yıl öncesi 2010 yılı için \%69,44 olarak hesaplanmıştır.

Çalışmada oluşturulan CHAID ve C 5.0 ve Lojistik Regresyon Analizi yöntemleri için oluşturulan modellerde 2012 yılı sınıflandırma doğrulukları en başarılı yıl olarak belirlenmiştir. CHAID Modeli 2012 yılı için 30'u doğru, 6'sı ise yanlış sınıflandırılmıştır. Modelin başarı oranı \%83,33 olarak hesaplanmıştır. C 5.0 Modeli 2012 yılı için 32'si doğru, 4'ü ise yanlış sınıflandırılmıştır. Modelin başarı oranı \%88,89 olarak belirlenmiştir. Lojistik Regresyon Modeli 2012 yılı için 34'ü doğru, 2'si ise yanlış sınıflandırılmıştır. Modelin başarı oranı \%94,44 olarak hesaplanmıştır. Modellerin sınıflandırma doğrulukları başka bir ifadeyle modellerin tahmin gücü karşılaştıııldığında Lojistik Regresyon modelinin daha başarılı olduğu saptanmıştır.
Çalışma, Veri Madenciliği ve Lojistik Regresyon Analizi yöntemlerinin işletmelerin finansal başarsızlıklarının yüksek düzeyde tahmin edilebilir olduğunu ortaya koymuştur. Dolayısıyla, işletmelerin başarısızlık durumunun bir çok çıkar grubunu olumsuz etkilediği gerçeğini her zaman göz önüne bulundurmak zorunda olan yöneticiler, bu yöntemleri kullanarak işletmenin finansal durumunu tahmin edebilirler. Bu bağlamda yöneticiler, çalışma sonucunda önemli olduğu görülen finansal yapı ve kârlılık oranları başta olmak üzere finansal oranlarla işletmenin başarısızlıklarını önceden tespit edebilecekleri ve ortaya çıkabilecek riskleri önleyebileceklerinin bilincinde olmalıdırlar. Bu oranları etkin kullanabilmek adına hem kendileri bu konuda eğitim almalı hem de çalışanların eğitim programlarına katılmaları sağlanmalıdır. Ayrıca düzenli olarak uzman bireylerden ve kuruluşlardan destek alınmalıdır.

Bu çalışma, imalat sanayi sektöründe faaliyette bulunan 143 işletme ve 4 yılı kapsayan verilerle sınırlıdır. Dolayısıyla ortaya çıkan sonuçlar bu sınırılık içerisinde değerlendirilmelidir. Daha genellenebilir sonuçlara ulaşmak farklı yöntemlerle farklı sektörleri kapsayan çalışmaları gerekli kılmaktadır. Bu çalışmada kullanılan her üç modelde de özellikle 2012 yılının tahmin gücünün yüksek olduğu sonucuna ulaşılmıştır. $\mathrm{Bu}$ sonucun gelecekte yapılacak çalışmalara katkı sağlayacağı düşünülmektedir. Bu bağlamda çalışma, yapılacak çalışmalar için bir başlangıç noktası olabilir. 


\section{KAYNAKLAR}

Akkaya, G.C., Demireli, E. ve Yakut, Ü.H. (2009) "İşletmelerde Finansal Başarısızlık Tahminlemesi: Yapay Sinir Ağları Modeli ile IMKB Üzerine Bir Uygulama", Eskişehir Osmangazi Üniversitesi Sosyal Bilimler Dergisi, 10(2): 187-216.

Aktaş, R., Doğanay, M. ve Yıldız B.(2003) “Finansal Başarısızlığın Öngörülmesi: İstatistiksel Yöntemler ve Yapay Sinir Ağı Karşılaştırması", Ankara Üniversitesi SBF Dergisi, 58(4): 1-24.

Albayrak, A. S. ve Yılmaz, Ş. K. (2009) “Veri Madenciliği: Karar Ağacı Algoritmaları ve IMKB Verileri Üzerine Bir Uygulama", Süleyman Demirel Üniversitesi Iktisadi ve idari Bilimler Fakültesi Dergisi, 14(1): 31-52.

Altaş, D. ve Giray, S. (2005) "Mali Başarısızlığın Çok Değişkenli İstatistiksel Yöntemlerle Belirlenmesi: Tekstil Sektörü Örneği", Anadolu Üniversitesi Sosyal Bilimler Dergisi, 5 (2): 13-28.

Altman, E.I. (1968) "Financial Ratios, Discriminant Analysis and Prediction of Corporate Failure", Journal of Finance, 23(4): 589-609.

Altman, E.l. ve Hotchkiss, E. (2010) Corporate Financial Distress and Bankruptcy: Predict and Avoid Bankruptcy, Analyze and Invest in Distressed Debt, 3th Edition, John Wiley\&Sons. Inc.

Atiya, A. (2001). “Bankruptcy Prediction For Credit Risk Using Neural Networks: A Survey and New Results", Neural Networks, 12(4): 929-935.

Beaver, W.H. (1966) "Financial Ratios as Predictors of Failure", Empirical Research in Accounting: Selected Studies, Journal of Accounting Research, 5: 71-111.

Beaver, W.H. (1968) "Market Prices,Financial Ratios and the Prediction of Failure ", Journal of Accounting Research, 6(2): 179-192.

Beaver, W.H., Correia, M. ve McNichols, M.F. (2011) Financial Statement Analysis and the Prediction of Financial Distress, Now Publishers Inc, USA.

Brealey, R.A., Myers, S.C., ve Marcus, A.J. (1997) İşletmelerde Finansmanın Temelleri, 2. Baskı, Çevirenler: Ünal Bozkurt, Türkân Arıkan ve Hatice Doğukanlı, Literatür Yayıncılık.

Gujarati, D.N. (2011) Temel Ekonometri, 8. Baskı, Çevirenler: Ümit Şenesen, Gülay Günlük Şenesen, Literatür Yayıncılık.

Koyuncugil, A.S. ve Özgülbaş, N. (2006) “iMKB'de İşlem Gören Kobi'lerin Finansal Başarısızlığına Etki Eden Faktörlerin Veri Madenciliği ile Belirlenmesi", 3. KOBI'ler ve Verimlilik Kongresi, İstanbul Kültür Üniversitesi, 17-18 Kasım.
Larose, D.T. (2005) Discovering Knowledge in Data: An Introduction to Data Mining, John and Wiley Sons Inc., USA.

Li, H. and Sun, J. (2011). "Empirical Research of Hybridizing Principal Component Analysis with Multivariate Discriminant Analysis and Logistic Regression for Business Failure Prediction", Expert Systems with Applications, 38(5): 6244-6253.

Mellahi, K. ve Wilkinson, A.J. (2004) "Organizat ional Failure: A Crit ique of Recent Research and a Proposed Integrative Framework", International Journal of Management Review, 5/6(1): 21-41.

Odom, M.D. ve Sharda R. (1990) "A Neural Network Model For Bankruptcy Prediction", International Joint Conference on Neural Networks, 2: 163-168.

Ohlson, J.A. (1980) "Financial Ratios and the Probabilistic Prediction of Bankruptcy", Journal of Accounting Research, 18(1), 109-131.

Okka, O. (2009) Analitik Finansal Yönetim, 1. Baskı, Nobel Yayın Dağıtım.

Özdamar, K. (2004) Paket Programlar ile İstatiksel Veri Analizi 1, Kaan Kitabevi.

Özdemir, F.S. (2011) "Finansal Raporlama Sistemlerinin Bilginin İhtiyaca Uygunluğu Açısından Değerlendirilmesi: IMKB Şirketlerinde Finansal Başarısızlık Tahminleri Yönüyle Bir Uygulama", Yayımlanmamış Doktora Tezi, Ankara Üniversitesi Sosyal Bilimler Enstitüsü.

Sharan, V. (2009) Fundamentals of Financial Management, Second Edition, Dorling Kindersley, India.

Shirata, C. Y. (1998) "Financial Ratios as Predictors of Bankruptcy in Japan: An Enpirical Research", Proceedings of The Second Asian Pacific Interdisciplinary Research in Accounting Conference, 1-17.

Siedlecki, R. (2014) "Forecasting Company Financial Distress Using the Gradient Measurement of Development and S-Curve", Procedia Economics and Finance 12: 597-606.

Tamari, M. (1966) "Financial Ratios as a Means of Forecasting Bankruptcy", Management International Review, 15-21.

Tang, T.C. and Chi, L.C. (2005). "Neural Networks Analysis in Business Failure Prediction of Chinese Importers: A Between-Countries Approach" Expert Systems with Applications, 29: 244-255. 
Tarı, R. (2011) Ekonometri, 7. Baskı, Umuttepe Yayınları.

Tsiptsis, K. And Chorianopoulos, A. (2009). Data Mining Techniques in CRM: Inside Customer Segmentation, John Wiley \& Sons.

Tükenmez, N.M. Demireli, E. ve Akkaya G.C. (2012) "Finansal Başarısızlığın Tahminlenmesinde Diskriminant Analizi, Lojistik Regresyon ve Chaıd Karar Ağacı Modellerinin Karşılaştırılması: Kobi'ler Üzerine Bir Uygulama", 16. Finans Sempozyumu, 1013 Ekim 195-218.
Vuran, B. (2008) "Şirketlerin Finansal Açıdan Sorunlu Olmasına İlişkin Model Çalışması: Türkiye Üzerine Bir Araştırma", Yayımlanmamış Doktora Tezi, İstanbul Üniversitesi Sosyal Bilimler Enstitüsü.

Yakut, E. ve Elmas, B. (2013) “İşletmelerin Finansal Başarısılığının Veri Madenciliği ve Diskriminant Analizi Modelleri ile Tahmin Edilmesi", Afyon Kocatepe Üniversitesi IïBF Dergisi, XV(I): 237-254.

Zmijewski, M.E. (1984)“Methodological Issues Related to The Estimation of Financial Distress Prediction Models", Journal of Accounting Research, 22: 59-82. 